\title{
QUAL A CONTRIBUIÇÃO DA SEMÂNTICA E DA PRAGMÁTICA PARA A AQUISIÇÃO DA COMPETÊNCIA COMUNICATIVA EM LÍNGUA ESPANHOLA? O MATERIAL DIDÁTICO SOB INVESTIGAÇÃO
}

\author{
WHAT IS THE CONTRIBUTION OF SEMANTICS AND PRAGMATICS TO THE \\ ACQUISITION OF COMMUNICATIVE COMPETENCE IN SPANISH \\ LANGUAGE? THE TEACHING MATERIAL UNDER INVESTIGATION
}

\author{
Recebido: 30/10/2020 Aprovado: 04/01/2021 Publicado: 10/01/2021
}

DOI: $10.18817 /$ rlj.v4i02.2404

Ana Lúcia Rocha Silva ${ }^{1}$

Orcid id: https://orcid.org/0000-0002-5435-9890

\author{
Thays Costa Lisboa de Sá ${ }^{2}$ \\ Orcid id: https://orcid.org/0000-0002-3988-6318
}

\begin{abstract}
Resumo: De caráter interdisciplinar, este trabalho tem como objetivo evidenciar a presença e importância de aspectos semânticos e pragmáticos em atividades de língua espanhola, cujo foco é a aquisição da competência comunicativa (CC), um dos conceitos-chave em Linguística Aplicada (LA). Ao apontar o lugar ocupado pela Semântica e Pragmática na formação de aprendizes competentes em língua estrangeira (LE), defendemos que a Semântica e a Pragmática, sendo uma interface da outra, dialogam com o conceito de competência comunicativa, uma vez que saber o significado da palavra rato em espanhol é tão importante quanto saber emprega-la, como e quando. Quanto à metodologia, a abordagem é qualitativa e o método bibliográfico (PAIVA, 2019). Para alcançar o objetivo proposto, contamos com as contribuições de Almeida Filho e Franco (2009), Cançado (2008), Widdowson (2005), Araújo (2007), dentre outros.
\end{abstract}

Palavras-chave: Semântica. Pragmática. Competência comunicativa.

Abstract: With an interdisciplinary character, this work aims to highlight the presence and importance of semantic and pragmatic aspects in Spanish language activities, whose focus is the acquisition of communicative competence (CC), one of the key concepts in Applied Linguistics (AL) . When pointing out the place occupied by Semantics and Pragmatics in the formation of competent foreign language (LE) learners, we defend that Semantics and Pragmatics, being an interface of each other, dialogue with the concept of communicative competence, once that knowing the meaning of the word rat in Spanish is as important as knowing how to use it, how and when. About the methodology, the approach is qualitative and the method is bibliographic (PAIVA, 2019). In order to achieve the proposed objective, we count on the contributions of Almeida Filho and Franco (2009), Cançado (2008), Widdowson (2005), Araújo (2007), among others.

\footnotetext{
1 Possui graduação em Direito pela Universidade Ceuma (2003), graduação em Licenciatura em Letras pela Universidade Federal do Maranhão (1981), mestrado em Linguística pela Universidade Federal do Ceará (2009) e doutorado em Linguística pela Universidade Federal do Ceará (2014). Professora associada do dep. de letras da Universidade Federal do Maranhão. E-mail: analurochas@hotmail.com

${ }^{2}$ Mestranda do Programa de Pós-graduação da Universidade Federal do Maranhão. Graduada em Letras Língua Portuguesa e Língua Espanhola e suas respectivas literaturas pela Universidade Federal do Maranhão (UFMA), com intercâmbio na Universidad Nacional Autónoma de México (UNAM). Pós-graduada em Língua Portuguesa e Literatura Brasileira pelo Instituto de Ensino Superior São Franciscano (IESF) e em Ensino de Língua Espanhola pela Faculdade Venda Nova do Imigrante (FAVENI). Professora de Língua Portuguesa da rede pública municipal de São Luís, de Língua Espanhola da rede pública estadual e preceptora do Programa Residência Pedagógica da CAPES, em parceria com a Universidade Estadual do Maranhão (UEMA). E-mail: thayscostalisboadesa@hotmail.com
} 
Keywords: Semantics. Pragmatic. Communicative competence.

\section{Introdução}

Com este trabalho, pretendemos estabelecer um diálogo entre a Linguística Aplicada (LA), a Semântica e a Pragmática, ao evidenciar a presença e importância de aspectos semânticos e pragmáticos em atividades de língua espanhola, cujo foco é a aquisição da competência comunicativa (CC). Neste sentido, temos como objetivo analisar uma atividade de língua espanhola, apontando o lugar ocupado pela Semântica e Pragmática na formação de aprendizes competentes em língua estrangeira (LE).

Acreditamos que para adquirir CC é indispensável ao aprendiz produzir linguagem, além de possuir conhecimentos específicos da língua que se quer aprender. Assim, não basta saber o estritamente linguístico, o sentido literal das palavras, compreender o texto em suas limitações materiais, é necessário romper fronteiras e contemplar o extralinguístico, reconhecer as intencionalidades, os objetivos comunicativos, usar a língua em situações interativas, capturar e negociar os sentidos produzidos.

Produzimos linguagem o tempo inteiro, através de nossa língua materna apreendemos e representamos o mundo, convivemos em sociedade ao estabelecermos contratos de convivência. Com a língua estrangeira deve ocorrer o mesmo. Aprender uma língua estrangeira, obter um nível desejável de competência comunicativa requer a orquestração de diversos conhecimentos. Entendemos que os materiais didáticos ocupam um lugar relevante na formação de aprendizes de

LE, assim, quando estes recursos pedagógicos se mostram preocupados com a CC, eles podem ser grandes aliados na formação de verdadeiros usuários da língua.

Neste trabalho, defendemos que a Semântica e a Pragmática, sendo uma interface da outra, dialogam com o conceito de competência comunicativa, e que por isso mesmo podem contribuir com a formação de aprendizes competentes na língua estrangeira. Saber o significado da palavra rato em espanhol é tão importante quanto saber emprega-la, como e quando. Uma vez que trabalhamos com o conceito mais amplo de competência, isto é, a noção de competência 
comunicativa, e que esta noção concebe a linguagem por um olhar holístico, portanto, não dicotômico, trataremos da Semântica e da Pragmática enquanto áreas complementares.

Quanto à metodologia, a abordagem adotada é qualitativa e o método bibliográfico (PAIVA, 2019). Também conhecida como pesquisa interpretativa ou naturalística, a pesquisa qualitativa busca compreender os aspectos mais profundos do objeto sob investigação, permitindo assim uma reflexão. Para sustentar esta discussão, contamos com as contribuições de Almeida Filho e Franco (2009), Cançado (2008), Widdowson (2005), Araújo (2007), dentre outros. Sendo assim, esperamos alcançar o objetivo proposto e contribuir com os estudos que tratam da competência comunicativa de aprendizes de línguas.

\section{O conceito de competência comunicativa no ensino de língua estrangeira}

De acordo com Almeida Filho (2009), a Linguística Aplicada, enquanto ciência, ganhou espaço no contexto da II Guerra Mundial, e sua origem está diretamente ligada ao avanço do ensino de línguas nos Estados Unidos naquele momento. Apesar de ainda se ocupar do ensino de língua estrangeira, a LA amadureceu e estabeleceu diálogos com outras áreas do conhecimento. Atualmente, inúmeras questões que tratam dos fenômenos linguageiros interessam aos linguistas aplicados, o que permitiu à LA ser entendida como uma área mestiça (MOITA LOPES, 2006) ou transgressiva (PENNYCOOK, 2006). No entanto, neste trabalho, trabalharemos com um dos conceitos-chave em LA, o de competência comunicativa.

Desde que o conceito de competência comunicativa (CC) fora apresentado por Dell Hymes (1971), o ensino de língua estrangeira (LE) ganhou novos contornos. Convém salientar, no entanto, que as contribuições teóricas de Hymes não tinham como foco o processo de ensino e aprendizagem de uma LE, uma vez que sua preocupação consistia em lançar mão de uma proposta capaz de perceber os fenômenos da linguagem em sua integridade. Ou seja, para ele, não era concebível dicotomizar a linguagem humana em competência e desempenho, conforme a proposição de Chomsky (1971).

No conceito de competência comunicativa estavam previstos 0 conhecimento sobre o sistema linguístico, governado pelas regras gramaticais (a 
competência); e a capacidade de manipular este conhecimento em situações interativas (o desempenho), e isto implicava a existência daquele que outrora fora excluído dos estudos da linguagem, o sujeito falante. Conforme Hymes, o usuário da língua, bem como suas marcas linguageiras e os fatores extralinguísticos não poderiam ficar de fora dos fenômenos da linguagem, apesar de a ciência exigir um objeto asséptico e mensurável.

O alcance do conceito de competência atingiu a área do ensino de línguas graças aos esforços de Canale e Swain (1996) que ofereceram um marco teórico, ampliando ainda mais a proposta de Hymes. É interessante destacar que, ao longo do tempo, o construto da competência comunicativa, proposto e reformulado por diversos autores, passou por um processo de refinamento, e sua sofisticação deixou o modelo cada vez mais complexo. Neste trabalho, nos ocuparemos apenas do modelo de Almeida Filho e Franco (2009), tendo em vista o seu alcance no contexto brasileiro.

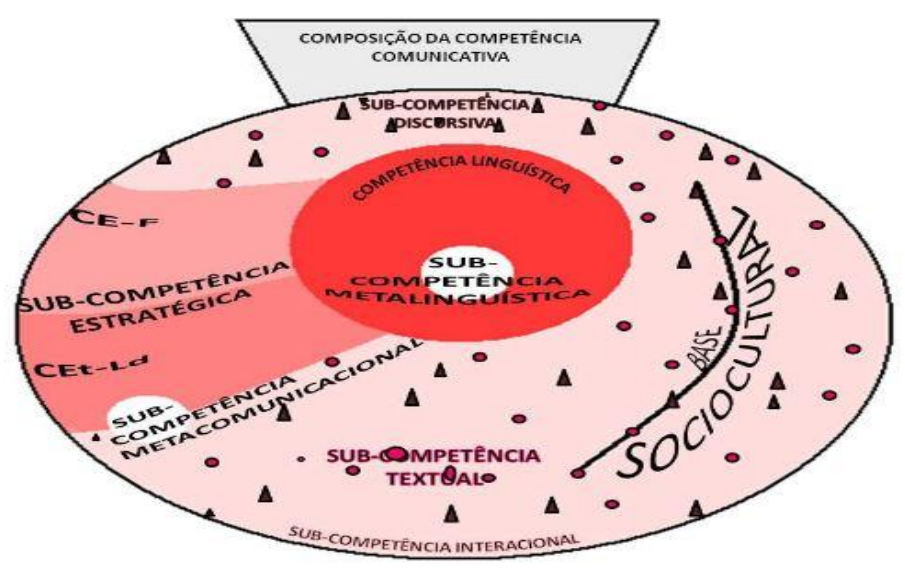

Figura 1 (Fonte: Almeida Filho e Franco, 2009)

No centro da competência comunicativa está a subcompetência linguística (I) e dentro dela, a subcompetência metalinguística (II). Estas duas subcompetências dizem respeito ao (I) conhecimento das regras gramaticais e ao (II) conhecimento e à capacidade de explicar a estrutura da língua por meio dos recursos que a própria língua oferece, usando as nomenclaturas aprendidas. (ALMEIDA FILHO \& FRANCO, 2009). Podemos ilustrar da seguinte maneira: o falante, de posse do conhecimento gramatical da língua que estuda, consegue 
explicar, por exemplo, no caso do espanhol, quando ou não usar o artículo neutro LO, explicitando as regras que justificam esse uso.

A subcompetência interacional (na parte inferior do modelo) "é a capacidade de colocar-se em comunicação com outros, seja ela oral ou por escrito", a subcompetência discursiva (na parte superior do modelo) "é a capacidade de manutenção do fluxo discursivo entre usuários de uma dada língua para a compreensão e expressão de significados situados num contexto", a subcompetência textual (logo acima da interacional) "caracteriza-se pela capacidade de composição e leitura de textos em gêneros distintos." (p.12). Em outros termos, além dos conhecimentos gramaticais e metalinguísticos (I e II), 0 falante precisa lançar-se em uma situação de interação na língua-alvo e conseguir mantê-la, levando em consideração os fatores contextuais. Além disso, é indispensável ao falante produzir e ler textos na língua estrangeira em diversos gêneros.

A subcompetência metacomunicacional (interconectada à subcompetência, à esquerda) refere-se à "capacidade do falante de uma língua de saber reconhecer e explicar verbalmente com taxonomia adequada aspectos relevantes da comunicação", já a subcompetência estratégica (acima da metacomunicacional) "refere-se aos componentes de compensação e de realce da comunicação, que são: formulaico, estético e lúdico". (p.13). A estratégica é composta por duas outras subcompetências, que são a competência estratégicoformulaica e a competência estético-lúdico, ambas "referem-se à capacidade de relacionar a aquisição da língua com a produção de um discurso sedutor e atraente capaz de manter o fluxo comunicativo" (p.13)

Para nós, a subcompetência metacomunicacional se assemelha à metalinguística, com a diferença de que em lugar de saber explicar e reconhecer os aspectos linguísticos, o falante deverá reconhecer e explicar os aspectos da comunicação (intencionalidades, negociação de sentidos, contratos de convivência, enfim.). Quanto à estratégica, entendemos que diz respeito às técnicas implantadas pelo falante para deixar o discurso mais atraente da mesma forma quando usamos paráfrases ou gestos na interação, tudo isso com o objetivo de sanar eventuais falhas na comunicação. Ou seja, o falante precisa lançar mão 
de estratégias que garantam a eficácia da comunicação, ou pelo menos, que possibilitem o mínimo de interferência.

\section{Semântica e Pragmática: uma fronteira movediça}

Existe uma discussão, (talvez) já envelhecida, a respeito dos limites da Semântica e da Pragmática. Há os que defendem a independência das áreas, por compreenderem que ambas são áreas autônomas, e os que acreditam que a Pragmática é um ramo da Semântica. Esta discussão não cabe neste trabalho, tendo em vista que juntas cumprem um papel relevante na aquisição de competência comunicativa.

Segundo Cançado (2008), à pragmática cabe descrever a linguagem em uso, levando em consideração as diferentes situações de fala. Assim, "a pragmática estuda a maneira pela qual a gramática, como um todo, pode ser usada em situações comunicativas concretas" (p.16), enquanto que a semântica se ocupa da "interpretação das expressões linguísticas, com o que permanece constante quando uma certa expressão é proferida" (p.17). No entanto, segue a autora, para entender os enunciados, não basta interpretar as expressões, é necessário capturar as intencionalidades daquele que enuncia.

Ora, quando nos lançamos em uma interação, certamente, não ficamos amarrados ao sentido literal das palavras, pois temos objetivos comunicativos a serem alcançados. Numa situação de instrução formal, na escola, por exemplo, é necessário explicar o conceito de um adjunto nominal, a forma como se apresenta nos enunciados, suas características (e estaríamos no nível semântico), mas o aluno também precisa compreender o uso e a finalidade de um adjunto em uma situação comunicativa (o que nos levaria ao nível pragmático). Algo semelhante acontece com o aprendiz de língua estrangeira quando a ele é apresentado a forma e o uso de uma expressão da língua.

Para Cançado (2008, p.18), "o objeto de estudo da pragmática é o uso das palavras e das sentenças inseridas em determinado contexto" e "a semântica não pode ser estudada somente como a interpretação de um sistema abstrato, mas (...) como um sistema que interage com outros sistemas, no processo da comunicação 
e expressão dos pensamentos humanos" (p. 19). Tomando como base a dicotomia chomskyana, a pragmática seria a ciência do desempenho.

Conforme Pinto (2016, p.43), "é preciso compreender muito mais do que os itens lexicais e as estruturas morfossintáticas para depreender o significado de um enunciado; é preciso, também, ter percepção de toda a situação comunicativa". Além disso, "o significado não envolve apenas o que é dito/escrito. Envolve o significado das palavras (significado lexical) e da sentença, e nosso conhecimento sobre comportamentos, intenções etc. (conhecimento de mundo)" (p. 45).

Desta forma, um ensino de língua estrangeira assentado, sobretudo, em aspectos gramaticais da língua, sem espaço para a interação, o diálogo, não estará contribuindo com o desenvolvimento da competência comunicativa. No caso da língua espanhola, é necessário experienciar a língua, para que os aprendizes percebam que embora semelhantes, a língua portuguesa e espanhola são diferentes e possuem características próprias. Levar o aprendiz a perceber as particularidades de cada idioma, pode favorecer a superação do portunhol. De acordo com Mota e Irala (2014, p. 95),

No contexto de aprendizagem de línguas, o termo portunhol pode ser empregado para se referir às produções realizadas por falantes de português como língua materna que estão aprendendo o espanhol, ou ainda, por hispanofalantes que estão aprendendo o português, como um processo em direção a proficiência da língua alvo.

Acreditamos que a interlíngua cumpre um papel essencial na busca pela proficiência na língua que se quer aprender, no entanto, no caso da língua espanhola, entendemos ser indispensável ultrapassar o portunhol e não se limitar a ele. Embora existam aqueles que se dão por satisfeitos quando conseguem se "virar" na língua-alvo, defendemos que aprender o idioma estrangeiro da forma como se apresenta, é também uma maneira de respeitar a cultura de um povo.

No ensino de língua estrangeira, produzir linguagem é essencial. Ao produzir linguagem, os aprendizes mobilizam diversos conhecimentos, os quais precisam estar articulados de maneira harmoniosa em seu discurso. Segundo Lopes (2006) o discurso, enquanto objeto de investigação, estabelece um elo entre a semântica e a pragmática, uma vez "a interpretação mobiliza diferentes e heterogéneos domínios de análise no plano da significação" (p.3). Neste sentido, não há como separar os aspectos semânticos dos pragmáticos, pois, a partir do 
momento em que é estabelecida uma dicotomia, o fenômeno linguístico é percebido apenas por uma óptica. Ao nosso ver, desintegrar o fenômeno, permite um olhar limitado sobre a linguagem humana.

Para Lopes (2006, p. 3), a pragmática se ocupa da significação construída no e pelo discurso. Segundo a autora, o discurso é "uma prática social que envolve um contexto situacional, actores dotados de intencionalidade e de capacidades inferenciais, universos de conhecimentos e crenças compartilhados ou em dissimetria". Assim, no jogo da interação, em situações comunicativas, entram em campo diversos fatores extralinguísticos, que não cabem em uma análise solitária de expressões linguísticas. Importam informações que ultrapassam a materialidade da língua, como: Quem disse? Como disse? Para quem? Onde? entre muitas outras.

\begin{abstract}
Sabemos que as línguas são empregadas no dia-a-dia das mais variadas maneiras e não de forma rígida. Os estudos discursivos e pragmáticos tentam esclarecer como se dá essa produção de sentidos relacionados aos usos efetivos: o sentido se torna algo situado, negociado, produzido, fruto de efeitos enunciativos e não algo prévio, imanente e apenas identificável como um conteúdo. (MARCUSCHI, 2008, p. 37)
\end{abstract}

Uma vez que o discurso envolve sujeitos falantes de uma língua, é possível estabelecer também um diálogo com a Linguística Aplicada (LA). De acordo com Rajagopalan (1999, p 332)

Se a preocupação no sentido de trabalhar com dados recolhidos da vida realmente vivida pelos usuários de língua e não inventados pela imaginação fértil dos pesquisadores une a pragmática às áreas como análise de discurso, análise conversacional, lingüística de texto, e sociolingüística, é de se esperar que os pesquisadores que se interessam pela pragmática também se interessem pelas questões que são tratadas sob o rótulo de "lingüística aplicada"

É interessante notar que, sendo a linguagem humana o objeto de investigação de diversas e diferentes áreas do conhecimento, não é de causar estranheza que em algum momento elas se entrecruzem e estabeleçam um diálogo. Podemos perceber esta relação, entre a LA e a pragmática, quando lidamos com a noção de competência comunicativa de aprendizes de língua estrangeira. Conforme assinalamos, ser competente significa, além de usar a língua, indica a possibilidade de transitar por diversos contextos de interação, reconhecer intencionalidades e objetivos comunicativos. 
Em LA, dentro dos limites do que estamos tratando neste trabalho, isto é, a noção de competência comunicativa, acreditamos que o aprendiz precisa conhecer vários aspectos da língua que estuda, tendo em vista que o objetivo principal é manipular conhecimentos em situações interativas. Acreditamos que para alcançar tal propósito, o de se comunicar, a semântica e a pragmática caminham juntas, conforme nos assinala Araújo

\begin{abstract}
Cada qual se caracteriza de modo próprio, semântica e pragmática podem e devem ser analisadas em seus próprios termos (...) Porém no uso lingüístico, esses níveis caminham juntos, por vezes se imbricam; a compreensão do dito (semântica) e a leitura do que é dito (pragmática) a alguém, através de um ato de fala, são duas faces da mesma moeda, para usar uma metáfora cara a Saussure. Ou seja, semântica e pragmática são complementares e imprescindíveis para significar algo pela linguagem, e para a comunicação linguística. (2007, p. 2)
\end{abstract}

A habilidade oral, a fala do sujeito falante, outrora rechaçada pela linguística hegemônica, alcançou seu lugar ao sol no ensino de línguas estrangeiras, pois a competência comunicativa abarcou a competência e o desempenho, e isto significa que a linguagem passa a ser concebida em sua integralidade. Assim, "sob um ponto de vista semântico-pragmático, a linguagem se caracteriza pelas funções de significar algo para alguém, num contexto, com um propósito e com sucesso argumentativo" (ARAÚJO, 2007, p. 23). Desta forma, ao usar este par de óculos, acreditamos que "a fala não é obstáculo epistemológico para ciência da linguagem; não só é possível estudá-la, como esse estudo aprofunda e enriquece a própria compreensão de linguagem, e, por conseguinte, de nós mesmos" (p. 13).

Concordamos com Widdowson (2005, p. 15) ao afirmar que aprender "uma língua abrange, portanto, a aquisição da capacidade de compor frases corretas (...). Mas ela também inclui a aquisição da compreensão de como essas frases, ou partes delas, são apropriadas num contexto especifico" e desta forma, o aprendiz conseguirá obter certos efeitos comunicativos. Ainda conforme o autor, "nós não manifestamos simplesmente o sistema abstrato de língua, mas também o fazemos fluir simultaneamente como comportamento comunicativo com significados". (p. 16)

A análise da palavra pior, por exemplo, não deve ser vista apenas sob o olhar da Semântica. Em solo maranhense, este vocábulo assume outras acepções e pode significar uma concordância com que o é dito, equivale a algo do tipo: É 
verdade! É mesmo! Com isto, queremos evidenciar que o valor do aspecto social da palavra, o uso e funcionamento da linguagem são tão fluídos que escapam de qualquer amarra ou imposição de limites.

Reconhecemos que aliar os estudos semânticos aos que tratam da pragmática talvez não seja uma opção viável ao gramaticista, uma vez que estará ocupado com o aspecto abstrato da língua, no entanto, quando se trata do ensino de língua estrangeira, entendemos que os estudos semântico-pragmáticos têm muito a contribuir para a aquisição de uma competência comunicativa. Primeiro, pelo fato de que mais uma dicotomia não seria benéfica ao processo de ensino e aprendizagem e, segundo porque a própria noção de competência comunicativa nos autoriza esta leitura.

\section{O material didático e a formação de aprendizes de LE}

Segundo Salinas (2005), o aprendiz brasileiro apresenta indícios de fossilização da língua espanhola desde o início do processo de ensino e aprendizagem, graças à crença de que as línguas portuguesa e espanhola são muito parecidas. Para o autor, a estagnação na interlíngua, isto é, no portunhol, acaba sendo alimentada pelos materiais didáticos voltados para o ensino da língua espanhola, pois "grande parte dos materiais (principalmente livros de texto) encontrados no Brasil para o ensino do espanhol não são específicos para brasileiros e sim para quaisquer outas línguas". (p.55)

A respeito do ensino assentado sobre a forma ou o uso, assinala Salinas (2005) que "se a metodologia for estrita e exclusivamente comunicativa, poderá levar o aluno a fossilizar sua interlíngua, usando o português com 'pinceladas' da língua-lavo". Ressalta que "a discussão sobre qual é melhor, um ensino/aprendizagem com enfoque comunicativo ou aquele com base na forma, nos faz pensar sobre as necessidades específicas dos nossos alunos" (p. 57). Isto significa que não devemos eleger uma maneira de ensino em detrimento da outra, como se estudar uma língua estrangeira exigisse ou o estudo da gramática ou a capacidade de usar a língua. Forma e uso não são opções excludentes entre si, são, antes de tudo, faces da mesma moeda. 
Salinas (2005) argumenta que a produção dos materiais didáticos deve ter em vista as necessidades dos aprendizes, o que diminuiria o tempo de aprendizagem e evitaria a fossilização da língua. Sugere que um "(..) material didático mais apropriado às necessidades dos alunos teria que levar em consideração, por um lado, (...) pontos que o português e o espanhol têm em comum, e por outro, os aspectos nos quais essas línguas diferem por completo". (p. 58). Desta forma, vemos que o material didático assume um papel relevante no processo de ensino e aprendizagem de uma língua estrangeira. Acreditamos que a qualidade e natureza do material pode possibilitar ao aprendiz ultrapassar a interlíngua e alcançar um nível de competência comunicativa desejável.

Silva (2005) se alinha ao mesmo pensamento, o de que é necessário produzir materiais de acordo com o alunado, tendo em vista algo pensado para nativos da língua portuguesa. A autora aponta dois traumas do estudante brasileiro ao tentar aprender a língua espanhola. O primeiro é a ideia de que o espanhol é fácil e se aprende rápido, esta expectativa uma vez não preenchida provoca frustração, e o segundo é o precário nível de conhecimentos gramaticais sobre a língua-alvo. Segundo ela, ao professor ou ao elaborador de textos didáticos para aprendizes cabe o desafio de

\begin{abstract}
“(...) proporcionar ao aluno textos e exercícios que, além de expor em língua espanhola novas informações, estruturas sintático semânticas desconhecidas, ou difíceis de aprender, etc. o estimulem a trabalhar de forma inovadora e criativa, na observação e uso de novas construções linguísticas, em todos os níveis, em relação à sua própria língua; sistematizar a proximidade e a diferença na análise linguística, para solucionar e superar dificuldades em seus processos de aquisição. (...)" (tradução nossa) $^{3}$
\end{abstract}

Para Almeida Filho (2012), os materiais didáticos devem ser produzidos a partir de consultas com os agentes envolvidos no processo de ensino e aprendizagem da língua estrangeira, tendo em vista as condições das escolas e das turmas. Conforme o autor, essa prática (de considerar os interesses e objetivos

\footnotetext{
${ }^{3}$ (...) proporcionar al alumno textos y ejercicios que, además de exponer en lengua española nuevas informaciones, estructuras semántico sintácticas desconocidas, o difíciles de aprender, etc. lo estimulen a trabajar de forma innovadora y creativa, en la observación y uso de nuevas construcciones linguísticas, en todos los niveles, en relación con su propia lengua; sistematizar la proximidad y la diferencia en el análisis linguístico, para solucionar y superar dificultades en sus procesos de adquisición. (SILVA, 2005, p. 184
} 
dos agentes) é fruto da abordagem comunicativa, surgida no país na década de 70 . Segundo Chaves e Coimbra (2018, p. 135),

\begin{abstract}
No processo de elaboração de coleções didáticas, é preciso ter em mente que há alunos tão diversos quantos as diversas culturas que convivem no Brasil e professores com diferentes crenças sobre o processo de ensinoaprendizagem de ELE, e que fazem uso de metodologias diferenciadas. (...). Acreditamos que as/ os autoras / es de livros didáticos devem estabelecer, antes de tudo, uma parceria intensa com os reais sujeitos do ensino-aprendizagem.
\end{abstract}

Desta forma, está claro qual o lugar ocupado pelo material didático na formação de aprendizes de línguas. Entendemos que este instrumento pedagógico não deve ser a única ferramenta de trabalho do professor, mas, sem dúvida, pode efetivamente contribuir com a formação de usuários competentes na língua-alvo. Reconhecemos que um material didático não é capaz de atender a todas as necessidades de alunos e professores, tendo em vista os diversos perfis de escolas, turmas e profissionais. Cada um desses agentes possui demandas específicas, muitas vezes não contempladas nos materiais, no entanto, acreditamos que uma formação crítica dos professores pode minimizar os eventuais impactos negativos na escolha dos materiais didáticos.

\title{
O material didático sob investigação
}

Nesta seção, faremos a análise de uma atividade de língua espanhola, apontando, quando possível, a presença de aspectos semânticos e pragmáticos e da competência comunicativa. Em primeiro lugar, no entanto, convém discutir um fato que nos chama bastante atenção. Em cada unidade do material didático (ver Fig. 2), é possível perceber vários aspectos da competência comunicativa de forma clara e objetiva, pois são contemplados os conteúdos

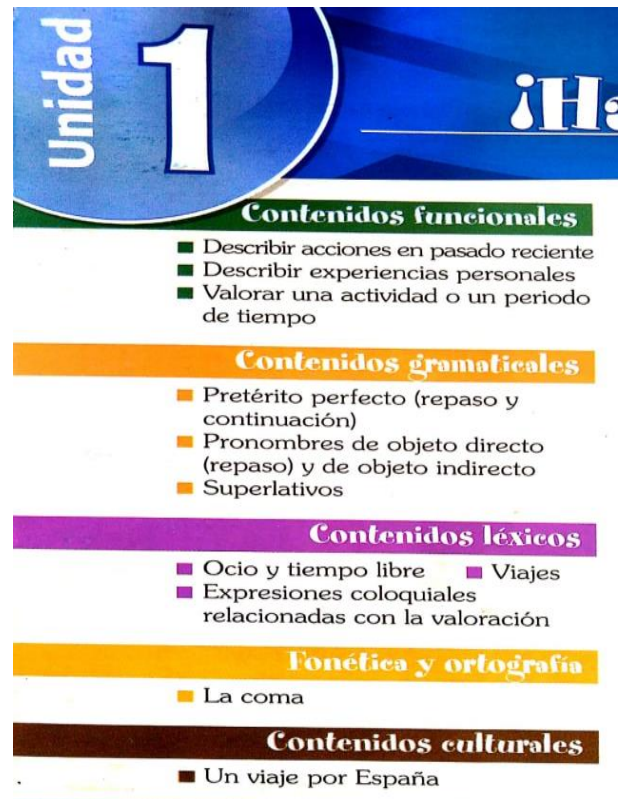

Figura 2 (Fonte: Espacio Joven) 
culturais, gramaticais e funcionais, além do estudo do léxico, da fonologia e da ortografia.

Conforme assinalamos, ser competente em língua estrangeira significa ter à disposição um repertório de conhecimentos, além da capacidade de uso. A forma de articular cada aspecto da CC em sala de aula, conforme proposto pelo material didático, ao nosso ver, dependerá da formação do professor de língua espanhola e da capacitação recebida para manusear este instrumento. Entendemos que trabalhar com um material desta natureza, requer a implantação de uma abordagem comunicativa, cujos princípios se coadunam com aqueles previstos no modelo de competência comunicativa. Em seguida, faremos a análise da atividade (ver Fig. 3).

\section{ช. ब(2) Escucha el diálogo y contesta las preguntas.}
a. ¿Qué ha hecho Paco en la montaña? $\Rightarrow$
b. ¿Cómo se lo ha pasado Marta? $\Rightarrow$
c. ¿Quién crees que es Javi? $\Rightarrow$
d. ¿Cuál ha sido la mejor experiencia de Paco en la montaña? $\Rightarrow$
e. ¿Cuál es el consejo que se desprende del diálogo? $\Rightarrow$

46 Lee ahora el diálogo y comprueba. Luego prepara algunas preguntas para hacer a tu compañero.

Paco: ¡Hola, Marta! ¿Qué tal el finde?

Marta: Bueno, un poco aburrido. He estado estudiando para el examen de Historia y casi no he salido. Y tú, ¿has hecho algo interesante? R. ¡Yo me lo he pasado genial! Hemos estado de acampada en la sierra.

M.: ¡Qué suerte! ¿Con quién has ido?

R.: Con mi vecino y su hermano mayor, que es un experto montañero. Él nos ha enseñado a montar solos una tienda de campaña y a usar el mapa y la brújula para no desorientarnos en el campo.

M.: ¡Qué divertido! Y, ¿dónde habéis dormido?

R.: Pues en las tiendas, en nuestros sacos de dormir. Lo mejor de la excursión es que he- mos visto una lluvia de estrellas por la noche. ¡Ha sido impresionante!

M.: ¿Y no os ha dado miedo encontraros con animales salvajes?

P: ¡No hombre, no! Además, con Javi nunca pasamos miedo, él sabe qué hacer en todo momento.

M.: Claro, es verdad. Mi padre siempre dice que a la montaña hay que ir con alguien experimentado.

P.: Sí, tu padre tiene razón. La montaña es fantástica, pero también peligrosa.

M.: ¡Qué envidia! ¡Para la próxima me apunto! Y... ya que yo no me lo he pasado tan bien, jespero al menos aprobar el examen de Historia!

Figura 3 (Fonte: Espacio Joven)

Inicialmente, na questão 3 , os alunos precisam ouvir o diálogo e em seguida responder às questões propostas, as quais procuram verificar 0 entendimento do aluno por meio das habilidades auditiva e escrita, nesta ordem. 
Para responder corretamente, o aluno deve apresentar um desenvolvimento satisfatório de compreensão auditiva da língua espanhola, caso contrário, não conseguirá escrever as respostas.

Algo que nos chama atenção é a ausência de uma lista com vocabulários, julgamos que isto decorre do fato de ser um material desenvolvido para o nível A2.2. Em relação à palavra finde, não há qualquer indicativo de seu significado. Em língua portuguesa, a escrita deste vocábulo se assemelha ao verbo findar, no entanto, uma vez que o sentido ficaria comprometido, certamente, o aprendiz em nível A2.2 não levantaria esta hipótese. Além disso, seria inconcebível supor que finde seria um verbo e não um substantivo, como de fato é.

Em todo caso, é bem possível que o aprendiz, já experiente neste nível, deduzisse ser uma gíria ou talvez soubesse o verdadeiro sentido dessa palavra. Considerando a não intervenção do professor, acreditamos que apenas após a leitura de todo o diálogo (talvez mais de uma vez), o aprendiz fosse capaz de entender que se trata de uma palavra descontraída da língua espanhola, e que poderia ser traduzida como FDS (fim de semana).

A palavra experto também merece um espaço nesta discussão. Experto poderia levar o aprendiz brasileiro a concluir que o irmão do vizinho de Paco é muito esperto, um astuto montanhista. Não que o sentido da palavra não desse margem a esta interpretação - seria até possível, aliás, se fosse em língua portuguesa - mas o sentido empregado neste contexto e em língua espanhola é o de especialista, isto significa que o irmão do vizinho de Paco é perito em montanhas. Recorrer ao dicionário, acionar o contexto de uso e atentar para o fato de que a língua estudada é a espanhola seriam os primeiros passos dados pelo estudante brasileiro para não ser traído pela sua própria intuição.

Quanto à palavra solos, para apreender o significado correto, o aprendiz precisa ter muito clara a diferença entre sólo e solo em espanhol. Enquanto que a primeira significa somente, a segunda quer dizer sozinho, portanto, sólo é um advérbio, invariável, e solo um adjetivo, variável. De posse desse conhecimento, o aprendiz saberia que se trata da palavra sozinhos. Aquele mais desavisado talvez 
fosse induzido ao erro, caso acreditasse ser solo sinônimo de terra, superfície. Daí vemos a importância do estudo léxico, dos falsos cognatos em língua estrangeira.

Quando Marta pergunta se eles não tinham ficado com medo de encontrar animais selvagens, Paco responde: ¡No hombre, no! A expressão “No hombre, no!" levada ao pé da letra, seria assim traduzida: Não homem, não! Tal expressão é possível em língua portuguesa, mas tendo em vista o significado social, as circunstâncias em foi empregado o termo e adequação à língua portuguesa, mais correto seria: Que nada! Claro que não! Além disso, uma vez o interlocutor de Paco é uma mulher, não é adequado considerar o valor linguístico da expressão, ignorando toda a construção de sentido que vem sendo articulado por Paco e Marta.

Temos algumas considerações em torno da expressão ¡Qué envidia! que em português seria: Que inveja! A palavra inveja representa algo ruim, pois é um sentimento mal visto pela sociedade, mas quando integra a expressão exclamativa, embora o seu valor literal não tenha sido excluído, significa algo do tipo: "Nossa! Você fez ou conquistou algo tão legal, que eu queria que também acontecesse comigo". Este sentido, apesar de não apagar o espírito negativo que carrega o vocábulo, é mais aceitável e normal do que assumir a existência de um sentimento tão desprezível. A expressão “Que inveja!" aponta para algo positivo, na atividade em análise, indica que a aventura nas montanhas foi uma experiência tão incrível que Marta também gostaria de experimentar, ou ainda, que o fim de semana de Paco foi tão bom que Marta gostaria de fazer o mesmo.

Evidentemente, que as expressões são mais facilmente compreendidas quando temos acesso a um conjunto de informações importantes como a entonação, as expressões faciais, o ritmo melódico, os gestos. Não basta apenas ter o conhecimento abstrato, é preciso recorrer aos fatores extralinguísticos. Para um estudante brasileiro, entender estes vocábulos de forma isolada e sem o seu contexto de uso, provocaria certas dificuldades. Se o aprendiz brasileiro se ativesse apenas ao o sentido literal, deslocado de sua condição de produção, sem evidências das circunstâncias do discurso, certamente o efeito produzido seria outro. Fazer uma análise asséptica das palavras analisadas poria em risco todo o sentido do discurso produzido. 


\section{Conclusão}

Para nós, está claro que a Semântica e a Pragmática têm efetiva contribuição a dar à formação de aprendizes competentes em língua estrangeira, por conta da abrangência e complexidade do construto da competência comunicativa. Produzir linguagem, por meio da LE, talvez seja o principal objetivo do aprendiz, no entanto, para alcançar o discurso torna-se necessário ultrapassar os limites impostos pelo ensino ainda amarrado aos pressupostos gramaticais.

A construção do sentido exige do falante o refinamento de certas habilidades, e o trabalho com diálogos em sala de aula cumpre um papel essencial quando articulados com os princípios da competência comunicativa. Além disso, atividades, como a analisada, guardam um grande potencial por apresentarem diferentes possibilidades de adquirir a capacidade de uso na língua ao mesmo tempo em que aprende o estritamente linguístico, o sentido literal das palavras. Levar o aluno a compreender que o ensino da língua estrangeira envolve 0 conhecimento linguístico e também o extralinguístico, os aspectos semânticos e pragmáticos, permite a ele perceber que a forma e o uso são faces da mesma moeda.

Entendemos que evocar o contexto de uso, identificar os objetivos comunicativos em atividades linguageiras, capturar as intencionalidades, transitar por diversos contextos e interagir por meio da língua estrangeira devem ser os objetivos do ensino de LE preocupado em formar usuários da língua. Chamar a atenção dos aprendizes brasileiros para certos aspectos da língua espanhola, o ajudará a romper as fronteiras da interlíngua, e permitirá sua evolução no processo de aquisição da competência comunicativa.

\section{Referências}

ALMEIDA FILHO, J. C. P. Dimensões comunicativas no ensino de línguas. 3ํㅡㄴ edição. Campinas, SP: Pontes, 2002. 
Campinas, SP: Pontes Editores, 2012.

Quatro Estações no Ensino de Línguas. 2ํㅡㄹ edição. - Linguística Aplicada Ensino de Línguas e Comunicação. 3o edição. Campinas, SP: Pontes Editores e ArteLíngua, 2009.

ALMEIDA FILHO, J. C. P. \& FRANCO, M. M. S. O conceito de competência comunicativa em retrospectiva e perspectiva. Revista Desempenho, Brasília, v 10, n1, p.04-22, jun. 2009.

ARAÚJO, Inês Lacerda. Por uma concepção semântico-pragmática da linguagem. Revista Virtual de Estudos da Linguagem - ReVEL. V. 5, n. 8, p-1-26, março de 2007.

CANÇADO, M. Manual de semântica: noções básicas e exercícios. 2o edição revisada. Belo Horizonte: Editora UFMG, 2008

CANALE, M. \& SWAIN, M. (1980). Fundamentos teóricos de los enfoques comunicativos. La enseñanza y la evaluación de una segunda lengua. Trad. Miguel A. Murcia. Revista signos. Teoría y práctica de la educción, 1996.

COIMBRA, L. S. CHAVES, L. S. Com a palavra, as autoras: um olhar para o livro didático como gênero discursivo e como objeto cultural. In: MATOS, D. PARAQUET, M. (org.). Interculturalidade e identidades formação de professores de espanhol. Salvador: EDUFBA, 2018, p. 219-244.

CHOMSKY, N. Aspectos de la teoría de la sintaxis. Madrid, Aguilar, 1971.

HYMES, D.H. Acerca de la competencia comunicativa. Trad. Juan Gómez Bernal. Departamento de Linguística. Universidad Nacional de Colombia, Santafé de Bogotá, 1972.

LOPES, A. C. M. Fronteiras entre Semântica e Pragmática: algumas reflexões. Faculdade de Letras. Universidade de Coimbra. 2006.

MARCUSCHI, L.A. Produção textual, análise de gêneros e compreensão. São Paulo: Parábola editorial, 2008.

MOITA LOPES, L. P. Uma linguística aplicada mestiça e ideológica: interrogando o campo como linguista aplicado. In: MOITA LOPES, L. P. Por uma linguística aplicada indisciplinar. SP: Parábola Editorial, 2006, p. 13- 42

MOTA, S.S. IRALA, V. B. O portunhol na formação de professores de espanhol como língua adicional. In: DE LIMA, L. M. (org.). A (in) visibilidade da América Latina na formação do professor de espanhol. Campinas, SP: Pontes editores, 2014.

PAIVA, V. L M. O. Manual de pesquisa em estudos linguísticos. $1^{\circ}$ ed. SP: Parábola, 2019. 
PENNYCOOK, A. Uma linguista aplicada transgressiva. In: MOITA LOPES, L. P. Por uma linguística aplicada indisciplinar. SP: Parábola Editorial, 2006, p. 67- 83.

PINTO, D. C. M. Semântica e Pragmática: divisão ou relação? In: PINTO, D.C.M. et al (orgs). Introdução à semântica. Rio de Janeiro: Fundação Cecierj, 2016

RAJAGOPALAN, K. Os caminhos da Pragmática no Brasil. D.E.L.T.A, São Paulo, vol 15, noe especial, 1999..

SÁNCHEZ, M.C.C. et al. Espacio Joven. Nivel A2.2. Livro do aluno. Editorial Edinumen, 2012.

SALINAS, A. Ensino de espanhol para brasileiros: destacar o uso ou a forma? In: SEDYCIAS, J. (org.). O ensino do espanhol no Brasil: passado, presente, futuro. São Paulo: Parábola Editorial, 2005, p. 54-60.

SILVA, A. Ensenãnza de español para brasileños In: SEDYCIAS, J. (org.). O ensino do espanhol no Brasil: passado, presente, futuro. São Paulo: Parábola Editorial, 2005, p. $182-194$

WIDDOWSON, H.G. O ensino de línguas para a comunicação. Trad. José Carlos Paes de Almeida Filho. 2ª edição. Campinas, SP: Pontes, 2005. 